\title{
Assistência técnica e financeira da união aos entes subnacionais: o desafio da equidade
}

\author{
State financial and technical asssitance \\ to subnational governments: the challenge of equity
}

\author{
Asistencia técnica y financiera de la unión de los gobiernos \\ subnacionales: el desafío de la equidad
}

\section{Edite Maria Sudbrack ${ }^{1}$ Nalú Farenzena²}

\section{Resumo:}

Este estudo propõe a análise da Assistência Técnica e Financeira da União aos entes subnacionais como o desafio da equidade. A pesquisa é de caráter qualitativo, propondo analisar em que medida as ações demandadas pelo Plano de Ações Articuladas (PAR) conduzem a maior equidade na oferta educacional. A política de transferência voluntária de recursos da União ao município envolvido na pesquisa é refletida através dos Termos de Compromisso firmada entre FNDE/MEC e gestor municipal, cotejando-os com as representações do gestor/sujeito da investigação. É flagrante no estudo que as dimensões do PAR que focalizam a atenção do município referem-se ao atendimento compulsório da educação infantil, pela Lei 12.756/2013, que torna obrigatória a matrícula aos 4 anos de idade na Educação Infantil. Entre as prioridades eleitas, destaca-se também o transporte escolar, envolvendo a projeção de aquisição de veículos para oferta deste serviço de apoio à educação escolar. Refere-se que, embora o Termo de Compromisso tenha sido pactuado pelo FNDE/MEC e município, parcela significativa de recursos não foram liberados, notadamente os recursos de informática, multimídia, entre outros. Entende-se que, num regime federativo cabe à União efetivar um papel redistributivo e supletivo de recursos técnicos e financeiros, na perspectiva de maior equidade da educação.

Palavras-chave: Assistência Técnica e Financeira; Equidade; Política Educacional; Plano de Ações Articuladas; Federalismo.

\footnotetext{
1 Doutora em Educação; docente do Programa de Pós-Graduação em Educação da Universidade Regional Integrada da Região das Missões (URI) Frederico Westphalen. E-mail: sudbrack@uri.edu.br.

2 Doutora em Educação; docente da Faculdade de Educação e do Programa de Pós-Graduação em Educação da Universidade Federal do Rio Grande do Sul (UFRGS). E-mail: nalu.farenzena@gmail.com.
} 


\begin{abstract}
:
This study aims to analyze the Technical and Financial Support from Brazilian Government to the subnational governments as an equity challenge. The research receives a qualitative basis and it intends to analyze in which way the demanded actions made by the Articulated Actions Plan (PAR) led to a major equity in educational offer. The policy of voluntary transfer of finantial resources from Brazilian Government to the city engaged in this research is reflected through the Terms of Commitment agreed between FNDE/MEC and a municipal manager, with this manager/individual being a representative of investigation during the process. It is glaring in this study that the dimensions from PAR that suggest the attention of the city refer to the compulsory assistance of the early childhood education, by the Law 12.756/2013. This Law forces the enrolment at 4 years old in early childhood education. Among the priorities of this work, we also highlight school transport, in which we involve the projection of vehicles acquisition that would be offered as a service to improve school education. It is referred that, despite this Terms of Commitment being agreed by FNDE/MEC and the city, a considerable part of resources was not provided yet; notably, the resources who would provide informatics, multimedia and others. We understand that, in a federative regime, The Union must act as the role of redistribute and supply technical and financial resources, in the perspective of more equity in education.
\end{abstract}

Keywords: Technical and Financial Support; Equity; Educational Policies; Articulated Actions Plan; Federalism.

\title{
Resumen:
}

Este estudio propone un análisis de la asistencia técnica y financiera de la Unión a las entidades subnacionales como el desafío de la equidad. La investigación es de carácter cualitativo, que propone examinar en qué medida las acciones demandadas por el plan de acciónes articuladas (PAR) conduzen a una mayor equidad en la oferta educativa. La política de transferencia de recursos financieros voluntarios al municipio que participa en esta investigación se refleja a través de los Términos de Compromiso de la Unión firmados entre FNDE/MEC y el administrador de la ciudad, comparándolas con las representaciones de los administradores/ objeto de la investigación. Llama la atención que las dimensiones del PAR que se centran la atención del municipio se refieren a la asistencia obligatoria de la educación infantil, por la Ley 12.756/2013, que ordena el registro de 4 años de edad en la educación parvulária. Entre las prioridades elegidas, que también se destaca el transporte escolar, que implica la proyección de la adquisición de vehículos para ofrecer este servicio para apoyar la enseñanza escolar. Se afirma que, aunque el Acuerdo de Compromiso ha sido acordada por el FNDE/ MEC y municipio, una parte significativa de los fondos no fueron enviados al município, en particular los recursos de tecnología de información, multimedia, entre otros. Se entiende que en un sistema federal es la Unión quien tiene el rol redistributivo y el papel complementario de los recursos técnicos y financieros, a favor de una mayor equidad en la educación.

Palabras clave: Asistencia técnica y financiera; Equidad; Política educativa; Plan de Acciones Articuladas; Federalismo. 


\section{Preâmbulo}

O texto trata da assistência técnica e financeira da União às demais esferas de governo. A pesquisa que deu origem ao texto é de caráter qualitativo e objetiva analisar, num município do norte do estado do Rio Grande do Sul, em que medida as ações de assistência voluntária da União, demandadas através do Plano de Ações Articuladas (PAR), têm incidido na equidade do atendimento educacional.

O Brasil encontra o século XXI tendo atingido, quase na totalidade, as metas de universalização da educação fundamental. Todavia, o grande gargalo ainda continua sendo, além do acesso e permanência, a aprendizagem de todos os estudantes. Esta perspectiva remete ao direito de todos e de todas em ter uma escola de qualidade, capaz do enfrentamento dos desafios postos pelo mundo do trabalho e da prática social. Entre os indicadores utilizados para aferir qualidade, o Brasil, à semelhança de outros países, utiliza-se da avaliação em larga escala. Destaca-se, para o foco deste estudo, o indicador derivado da Prova Brasil e do fluxo escolar, o Índice de Desenvolvimento da Educação Básica (IDEB), o qual sinaliza o desafio de imprimir qualidade à oferta de educação fundamental.

Nossa história recente é povoada de planos e programas que nem sempre resultaram em sucesso. Marcados pela tecnocracia, revelam a incapacidade dos governos em fazer frente à totalidade da complexa trama social. No contexto de descaso com as demandas da educação, seja em âmbito federal, seja dos governos subnacionais, há um clamor generalizado quanto ao baixo desempenho do sistema educacional brasileiro, tanto em avaliação nacional, quanto internacional.

A União, através de programas de assistência técnica e financeira de caráter voluntário, insere o baixo IDEB como um dos requisitos para a efetivação desta assistência, desde que escolas ou municípios construam planos de ações articuladas, firmando termos de compromisso com o Fundo Nacional de Desenvolvimento da Educação (FNDE), órgão do Ministério da Educação (MEC) responsável pelo gerenciamento dos recursos de assistência voluntária.

No município pesquisado, localizado na região norte do Rio Grande do Sul, de economia micro fundiária e de subsistência, o IDEB está abaixo da meta e da projeção nacional. Tal cenário impulsionou este estudo, a fim de discutir em que medida as ações de assistência efetivadas pela União estão contribuindo com a equidade da oferta da educação fundamental na rede municipal de ensino, tendo em conta o preceito constitucional de oferta de assistência técnica e financeira da União aos demais entes federados.

Nesta perspectiva, a política de transferência voluntária de recursos da União carece de esforço analítico, situando seu impacto na equidade da oferta e na prestação de contas à sociedade dos recursos públicos investidos. Em âmbito nacional, são perceptíveis as assimetrias regionais em termos educacionais, derivadas em parte das desigualdades econômico-sociais entre os entes federados. Tal condição acaba determinando ofertas desiguais dos bens educativos, o que convoca o papel supletivo e redistributivo da União com vistas à promoção de maior equidade.

\section{Transferência voluntária e equidade}

Para evitar lacunas no atendimento da educação, a Constituição Federal preconiza atribuições para todas as esferas de governo. A responsabilidade pela oferta de educação básica recai sobre estados, Distrito Federal e municípios, mas é dever da União exercer função redistributiva e supletiva, de forma a garantir a equalização das oportunidades educacionais e padrões mínimos de qualidade de ensino, mediante assistência técnica e financeira aos governos subnacionais. Portanto, a assistência da União na educação tem a promoção da equidade como um dos objetivos, pelo qual a pesquisa realizada buscou focar um dos modos dessa assistência - a de caráter voluntário - tendo em conta este princípio. 


\section{Equidade: apreendendo o conceito}

O conceito de equidade tem sua gênese nos estudos de Aristóteles em obras como "A Retórica" e "Ética a Nicômano", nas quais relaciona justiça e equidade, [...] "justiça e equidade não são absolutamente idênticas nem geneticamente diferentes" [...]. Neste sentido, a equidade embora justa, é uma retificação de uma injustiça (ARISTÓTELES, 2009, p. 109).

Sob este ponto de vista, a lei é, por vezes, estática e ampla e, para corrigi-la, Aristóteles, propõe a equidade, assim: "esta é a natureza essencial do equitativo, ou seja, uma retificação da lei onde a lei é lacunar em função de sua generalidade (ARISTÓTELES, 2009 p. 110).

Como as leis são universais, não exercem ação de forma idêntica em todas as instituições. Assim, a equidade está acima de uma justiça em particular, mas não está acima da justiça de modo mais amplo. A equidade então, presta-se à garantia de direito, independentemente do aspecto universal da lei.Para o pensador grego, a equidade propõe-se a corrigir a lei, quando a mesma não atende a todos.

O filósofo político norte americano, John Rawls (2008), em sua teoria, desenvolve em suas obras uma teoria da justiça como equidade. O autor faz uso do contrato social, justificando tal concepção. Através da teoria do contrato social, Rawls afirma que os cidadãos poderiam escolher princípios de justiça que sustentariam o tecido social. De forma resumida, pode-se afirmar que para Rawls, superar as injustiças dar-se-á pelo princípio da equidade. A perspectiva da equidade, portanto, rege suas ideias sobre o que é justo, esta representa a garantia de justiça social. Em suas palavras: "[...] a ideia mais fundamental nessa concepção de justiça é a ideia de uma sociedade como um sistema equitativo de cooperação que perpassa de uma geração para outra" (RAWLS, 2002, p.7).

Ao refletir sobre a teoria de justiça percebe-se seu potencial para reduzir as desigualdades através de políticas educacionais focadas em segmentos específicos. Este aspecto contribui para o entendimento das políticas de assistência voluntária da União aos entes federadas, no bojo de uma sociedade marcada por desigualdades, notadamente na educação. Neste sentido, ações dirigidas aos segmentos vulneráveis, conduzirão a maior equidade, abrandando as injustiças. A equidade conota o tratamento das diferenças de forma diferente, para então possibilitar uma determinada igualdade objetivada previamente.

Do ponto de vista etimológico, igualdade e equidade são equivalentes já que a igualdade se refere à iniciativa de reconhecer igualmente o direito de cada um e equidade é a qualidade ou estado de igual. Para Amartya Sen (2000), uma sociedade justa é a que dispõe de igualdade de oportunidades para todos, que se entende como sendo dar a todos o mesmo ponto de partida.

A palavra de ordem da igualdade, face ao novo cenário econômico e social, faz surgir uma inflexão ao preceito da igualdade. Narrativas hegemônicas sobre relações da educação com a economia introduzem uma nova retórica no campo das políticas educacionais: eficácia, eficiência, meritocracia, responsabilidade, entre outras, ocupando o espaço da igualdade de oportunidades. Com efeito, o palco dos anos de 1990, marcado pela reestruturação da economia global, do neoliberalismo, faz emergir o conceito de equidade na gramática educacional contemporânea.

A ótica da equidade presente nas políticas educacionais permite situá-la no contexto de orientações do Banco Mundial e na lógica compensatória. Diferentemente das políticas de igualdade de oportunidades, tal racionalidade aponta para o discurso da equidade, orientado pelo ideário neoliberal (CASSASUS, 2002).

O conceito de equidade empregado neste estudo, contudo, não diz respeito à perspectiva das políticas neoliberais. Apropriamo-nos das conotações presentes nas obras e Rawls e Sen, ou seja, a equidade, na ação pública na Educação, significa priorizar segmentos populacionais em situações mais desfavoráveis, a fim de permitir igualdade de condições de acesso e permanência na escolarização.

Feito este parêntese, retoma-se a narrativa acerca da assistência voluntária da União, via PAR. 


\section{A assistência voluntária da união: o papel do PAR}

A Assistência da União pode ser obrigatória ou voluntária. A assistência obrigatória diz respeito ao preconizado pela legislação, a assistência voluntária é diversa, desde formação docente, até infraestrutura física e material para as escolas. O Plano de Ações Articuladas, desde 2007, é uma das condições para efetivação da assistência voluntária da União aos entes federados subnacionais. Este é o foco do estudo, mais especificamente, a análise do Plano de Ações Articuladas (2011-2014) efetivado por um município no norte do Rio Grande do Sul.

É flagrante, no Brasil, a evolução positiva da universalização do ensino fundamental em termos de cobertura, todavia, se tomarmos como referência o preceito, estabelecido na Constituição Federal por meio da Emenda $n^{\circ}$ 59/2009 e na Lei de Diretrizes e Bases da Educação Nacional (LDB) por meio da lei n 12.796/2013, que torna obrigatória a escolarização na faixa etária de 4 a 17 anos, há ainda um caminho árduo, somado aos desafios de maior qualidade do processo.

Nesta perspectiva, a adesão ao PAR concorre para que estados e municípios comprometam-se com metas e ações e, em contrapartida, sejam beneficiados com assistência técnica e financeira voluntária da União. O aporte de um maior volume de recursos financeiros poderá concorrer para reduzir desigualdades entre regiões, aliado a um maior compromisso dos entes federados.

Na organização da educação brasileira, a União é incumbida da manutenção e organização da rede pública federal de ensino, bem como de auxiliar técnica e financeiramente os governos subnacionais, na perspectiva de maior qualidade de educação e equidade da oferta. Tais prerrogativas são condições para garantia do preceito redistributivo e supletivo na ação da União, previsto na Constituição Federal e na LDB.

A efetividade de tais prerrogativas dá-se também através dos programas de assistência técnica da União. Situando as principais políticas de assistência técnica e financeira da União, apontam-se aquelas de transferência automática, tais como Programa Nacional de Alimentação Escolar (PNAE); Programa Dinheiro Direto na Escola (PDDE); complementação ao Fundo de Manutenção e Desenvolvimento da Educação Básica e de Valorização dos Profissionais da Educação (FUNDEB); e Programa Nacional de Apoio ao Transporte do Escolar (PNATE), ações estas sob a tutela do Fundo Nacional de Desenvolvimento da Educação (FNDE), ligado ao Ministério da Educação (MEC).

Voltando a lente para aqueles programas de transferência voluntária da União aos entes subnacionais, cujo desencadeamento deu-se com o Plano de Metas Compromisso Todos pela Educação e deflagrado em 2007, no governo Lula. Segundo Farenzena (2012a, p. 195) "[...] a adesão ao Plano de Metas é, desde 2007, requisito para que os governos estaduais e municipais habilitem-se a receber transferência voluntária da União". Face importante do "Compromisso Todos pela Educação" é a ação dos governos com base nos indicadores apurados. Através de acordos do MEC com as redes de ensino para que assumam compromisso com as metas de elevação dos índices, há o benefício do aumento de recursos de modalidades Programa Dinheiro Direto na Escola (FERNANDES; GREMAUD, 2009).

A problematização das responsabilidades da União para com os resultados educacionais faz-se imprescindível já que o contingente de encargos da União para com a Educação Básica, cumprindo com o preceito constitucional de exercer a função supletiva e redistributiva, é inadiável. Sabe-se, contudo, que persistem desigualdade de acesso, permanência e qualidade da oferta entre regiões brasileiras. No entendimento de Farenzena (2012b, p. 15):

Não são os valores de assistência da União à Educação Básica das redes estaduais e municipais atualmente praticados que garantirão maior justiça escolar, seja qual for a dimensão considerada: igualdade de acesso, de oportunidade ou de resultados da educação.

A Constituição Federal, em seu artigo 211, preconiza: "A União, os Estados, o Distrito Federal e os Municípios organizarão em regime de colaboração seus sistemas de ensino". Em que pese o preceito constitucional e a prescrição de assistência técnica e financeira da União aos demais entes estatais, segundo Farenzena (2012b, p.13) este dispositivo "assumiu traços distintivos ao longo do tempo, evidenciando que as responsabilidades governamentais prescritas na legislação são, de fato, passíveis de (re) criações, demarcadas por contextos políticos e de configuração de finanças públicas". 
No ano de 2007, através do Decreto 6.094/2007, instituiu-se no Brasil o Plano de Metas, vinculado ao PDE, contendo entre os mecanismos para desencadeá-lo, o Plano de Ações Articuladas PAR. O Plano de Metas incorpora além do PAR, mecanismos de monitoramento e acompanhamento e controle da educação, sobressaindo-se o IDEB, gestão educacional, modo de assistência técnica da União, aos Estados e municípios, entre outros.

O Plano de Metas, como política inserida no PDE tem como propósito fazer avançar a qualidade da educação básica, a partir das diretrizes que transitam pelo acesso e permanência, gestão de sistemas e redes, formação docente entre outros. O caráter federativo do plano sinaliza para o regime de colaboração entre as esferas do governo nacional e subnacional. Para fazer frente ao Plano de Metas, os estados e municípios elaboraram seus Planos de Ações Articuladas, dando ênfase ao alcance de metas previstas, e por decorrência, à elevação do IDEB. O PAR apresenta-se como um novo critério para que a União transfira, voluntariamente, à educação básica, assistência técnica e financeira, diferentemente das transferências legais e automáticas, tais como PDDE, PNLD, PNAE, entre outros.

O Plano de Ações Articuladas consubstancia o apoio técnico ou financeiro da União de forma mais efetiva, a partir da Lei 12.695/2012, cujo teor apregoa o objetivo de 'promover a melhoria da qualidade da educação básica pública, observadas as metas, diretrizes e estratégias do PNE' (art.1º, parágrafo único). Tal legislação amplia as atribuições do PAR, incorporando objetivos do Plano de Metas. De igual forma insere-o no Plano Nacional de Educação (2014-2024), dando mais organicidade ao planejamento educacional.

As ações previstas no PAR têm caráter estratégico, assentadas no regime de colaboração entre os entes federados. Sob tal ponto de vista, exige-se sintonia entre União e municípios na realização e efetividade das ações e subações do PAR planejadas pelos municípios. Ainda que as subações estejam articuladas à responsabilização do ente municipal, requer articulação com a União para que de fato se concretizem.

Ressalta-se que a nova regulamentação, da lei 12.695/2012, aboliu os convênios, substituindo-os por Termos de Compromisso, assinados entre o executivo e o FNDE. O controle e o acompanhamento cabem ao Conselho do FUNDEB. Nesta perspectiva:

0 Termo de Compromisso garantirá à União que os entes recebedores dos recursos federais se comprometam, além da regular utilização de recursos, com os princípios da política nacional de educação básica de qualidade (BRASIL, 2012, p.2).

Entre as inovações da Lei 12965/2012, refere-se a que estabelece o Comitê Estratégico do PAR na esfera do Ministério da Educação, contendo atributos de controle, revisão das ações de assistência da União, tendo em sua composição representantes do CONSED e UNDIME. Na esteira das características do PAR, visualiza-se a ênfase no planejamento de cada ente nacional, sobressaindo-se o IDEB como importante mecanismo para acompanhar a evolução dos resultados e também como forma de regulação dos sistemas subnacionais.

Para Farenzena e Marchand (2013, p.802):

[...] as modificações imprimidas pela Lei 12.695/12, pela criação do Comitê Estratégico do PAR, assim como pela nova forma de transferência de recursos, na qual os Termos de Compromisso buscam reforçar a pactuação e as responsabilidades, evidenciam, respectivamente, tendências de incorporar representação mais orgânica das esferas subnacionais nas decisões [...].

No sistema federativo do Brasil, a relação entre os municípios e a União, constitui-se fundamental no contingente de responsabilidades que a esfera municipal tem assumido para fazer face ao direito à educação. No bojo destas atribuições, o aparato legal tem estabelecido mecanismos para que a União empreste auxílio técnico e financeiro aos entes federados. A CF de 1988 traduz este dispositivo ao determinar o papel redistributivo e supletivo do ente federal, no sentido de alavancar maior qualidade e cobertura da educação obrigatória. Este preceito ganha novos contornos com o PAR, no sentido de regrar e prover a assistência voluntária da União para com a educação básica. O Plano de Ações Articuladas configura-se como um instrumento de Gestão da educação dos municípios, integra-se ao PNE, e articula-se à assistência da União, condicionada, porém, ao alcance das metas e exigências previstas no Termo de Compromisso. 
Com o PAR, são revisitadas prerrogativas de redistribuição e suplência da transferência técnica e financeira da União aos estados, Distrito Federal e municípios. O artigo $2^{\circ}$ da lei 12.695/2012 apregoa que a elaboração do PAR será feita pelos entes federados e pactuado com o MEC. Em seu parágrafo $1^{\circ}$, apresenta as áreas de atuação, a saber: "I Gestão educacional; II Forma de profissão da Educação; III Práticas pedagógicas e avaliação; IV Infraestrutura física e de recursos pedagógicos” (BRASIL, 2012).

Há que considerar que o PAR precisa romper com antigas práticas de planejamento burocrático, garantindo maior participação nos processos de planejamento e gestão educacional, superando os aportes gerenciais e regulatórios. Significaria avançar para que a centralidade da educação transponha a esfera do discurso, para efetivar-se como prática democrática e emancipatória. Assim não se pode prescindir de investimento, gestão democrática, articulação entre os entes federados, condições de trabalho e carreira dos docentes, aspectos já amplamente conclamados.

\section{A realidade em foco}

\section{O lócus da pesquisa}

O Brasil, de acordo com os dados do IBGE 2010, apresenta uma população de 190.732.694 habitantes, distribuídos em 5.565 Municípios. O Rio Grande do Sul, situado na região sul do país possui 10.693 .929 de habitantes e um total de 496 Municípios. O município sede desta pesquisa localiza-se no Noroeste do Rio Grande do Sul, possui uma população de quase trinta mil habitantes. Deste contingente populacional, buscou-se identificar a quantidade de estudantes nas séries finais do Ensino Fundamental e do Ensino Médio na rede pública, de 2005 a 2012 (Tabela 1).

Tabela 1 - Matrículas na rede pública em Frederico Westphalen (2005- 2012)

\begin{tabular}{|c|c|c|c|}
\hline ANOS & ENSINO FUNDAMENTAL SÉRIES FINAIS & ENSINO MÉDIO & TOTAL \\
\hline 2005 & 2.030 & 1.497 & 3.527 \\
2006 & 2.004 & 1.407 & 3.411 \\
2007 & 1.955 & 1.375 & 3.330 \\
2008 & 1.905 & 1.407 & 3.312 \\
2009 & 1.911 & 1.419 & 3.330 \\
2010 & 1.884 & 1.398 & 3.282 \\
2011 & 1.855 & 1.327 & 3.182 \\
2012 & 1.589 & 1.335 & 2.924 \\
\hline
\end{tabular}

Fonte: INEP (2013)

No município, observa-se que, assim como nos dados para o Brasil e para o Rio Grande do Sul, as matrículas foram diminuindo neste período de sete anos; o número de alunos dos anos finais do Ensino Fundamental e Ensino Médio da rede pública reduziu em 603 como mostra a Tabela 1. Esse número representa uma retração de aproximadamente 17,1\%; a diminuição foi de 22\% nos anos finais do Ensino Fundamental e de 11\% no Ensino Médio. Estes alunos estão distribuídos em: uma escola federal, somente de Ensino Médio; nove escolas estaduais de Ensino Fundamental - Anos Finais; duas escolas estaduais de Ensino Fundamental Anos Finais e Ensino Médio; uma escola estadual de Ensino Médio; e seis escolas municipais de Ensino Fundamental Anos Finais.

De modo geral, observa-se uma redução nas matrículas nos anos finais do Ensino Fundamental e no Ensino Médio na rede pública, tanto em nível nacional como local. De acordo com o INEP, esse decréscimo é a acomodação do sistema com melhoria nos índices da distorção idade-série do Ensino Fundamental. Mas não é o objetivo desta pesquisa analisar as causas da redução de matrículas, mas vislumbrar a assistência da União a este Universo escolar. 


\section{Achados de pesquisa}

Termos de Compromisso

A análise dos achados de pesquisa orbita no tripé dos seguintes elementos: termos de compromisso; representação de gestores; Plano de Ações Articuladas. Tenta-se, na sequência, entabular um diálogo entre tais elementos, a grelha teórica e o conhecimento do contexto por parte de uma das autoras deste artigo.

Embrenhando-se na análise do Plano de Ações Articuladas (2011-2014), em termos de assistência técnica e financeira da União, a implementação do PAR revela-se inovadora na assistência aos entes subnacionais, o que vale também para o Município investigado. As relações federativas entre os entes nacionais podem ser analisadas a partir dos Termos de Compromisso (TC) firmados entre o MEC (FNDE) e o Município. Neste sentido, tomam-se os TC do período de 2011 a 2014, dialogando com as representações dos sujeitos, apuradas em entrevista semiestruturada.

Pesquisando a página na internet do MEC-FNDE ${ }^{3}$, tem-se a possibilidade de conhecer os termos de compromisso assinados entre as partes, ou seja, Município e FNDE.

Analisando o TC 536/2011, encontramos o Programa "Caminho da Escola" o qual se destina à compra de ônibus escolar padronizado, para o transporte escolar da rede de ensino. Esta prioridade revela a complexidade no atendimento ao transporte de estudantes de toda a rede, por parte do município. No caso do município em questão, toda a clientela do Ensino Médio precisa ser transportada já que o município oferece somente até o $9^{\mathrm{a}}$ ano do Ensino Fundamental. Neste TC, o município previu a aquisição de três veículos, no valor total de $\mathrm{R} \$ 561.760,00$. O transporte dos alunos para as escolas de nível médio impõe-se como necessário, face à objetividade legal de escolarização dos 4 aos 17 anos pela Lei 12.796/2013.

No exercício de 2012, há um TC destinado a equipamentos, veículos, projetos, mobiliários e eletrônicos, num total de $\mathrm{R} \$ 954.765,90$.

No exercício de 2013, encontra-se um registro de assistência técnica da União, no valor de $\mathrm{R} \$ 158.750,00$, destinado a equipar as salas de aula com lousa digital e para aquisição de notebook educacional. Segundo apontado pelo gestor, este Termo de Compromisso não foi atendido na totalidade.

Através de verbas do Plano de Aceleração do Crescimento (PAC/2013, o município percebeu valores na ordem de $\mathrm{R} \$ 184.583,84$, direcionados à construção de quadra escolar no interior do município. Dotar as escolas da zona rural de condições materiais adequadas reveste-se de potencial para contribuir com maior qualidade e equidade da oferta educativa.

Em 2014, através do $\mathrm{PAC}_{2}$, o município solicitou recurso no montante de $\mathrm{R} \$ 827.951,06$ para construção de escola de educação infantil, através do Pro-infância. Conforme relatado pelo gestor, as escolas estão em funcionamento, oferecendo maior número de vagas. A universalização do atendimento, revela-se uma constante face à exiguidade de vagas para dar conta destas prerrogativas até 2016.

O PAR de 2013 também possibilitou ao município a transferência de recursos financeiros do FNDE, num total de $R \$ 19.937,56$, utilizada para aquisição de material pedagógico para a educação infantil. Em 2014, através do PAR, a União, via FNDE, transferiu valores na casa de $\mathrm{R} \$ 83.005,16$ para o município, a fim de adquirir equipamentos para a educação infantil. Com efeito, não basta construir prédios, é preciso equipar as instituições com recursos materiais e pedagógicos para fazer frente à complexidade desta etapa da escolarização que é a educação infantil.

Os relatórios extraídos dos TC permitem verificar várias incidências de recursos financeiros para a Educação Infantil e para o Transporte Escolar, ainda que o PAR tenha proposto metas em todas as dimensões estabelecidas pela legislação. A ênfase no transporte escolar é uma necessidade do município que realiza o transporte escolar

3 Disponível em: <http://www.fnde.gov.br/>. 
da rede estadual de ensino, tendo recebido veículo do Estado para esta finalidade, conforme já assinalado. No tocante à Educação Infantil, cabe lembrar a implantação da obrigatoriedade da matrícula na pré-escola. Como incumbe aos municípios prover o atendimento à demanda da educação infantil e pré-escola (4 e 5 anos), o desafio é imenso e complexo, seja em termos de infraestrutura física, prédios e equipamentos, seja em recursos humanos com titulação compatível.

\section{O PAR do Município}

Ao analisar o PAR do município envolvido na pesquisa, encontram-se ações nas diferentes dimensões previstas.

A dimensão n ${ }^{\circ} 1$ abarca a Gestão educacional em diferentes áreas de atuação. O primeiro propósito envolve a gestão democrática, prevendo o acompanhamento do Plano Municipal de Educação. Esta dimensão também propõe consolidar o Conselho Municipal de Educação, incluindo a elaboração de um Plano de Ação. Preconiza ainda, a criação de Conselho Escolar, incentivando a integração entre conselhos e seu acompanhamento. Sinaliza, ainda, para a qualificação do pessoal técnico da secretaria para orientar os conselhos escolares. Conforme relatado pelo Gestor, a elaboração do PAR e sua implementação foram conduzidas pela equipe técnica da Secretaria Municipal de Educação, o que torna frágil o processo de participação e da gestão democrática. Assim: "os gestores de políticas públicas [...] são os autores que tem o papel preponderante no processo divisório das políticas de governo nos seus diversos níveis [...]" (MAFASSIOLI, 2012, p.9). Tal lógica exige reflexões para haver maior compromisso de todos os envolvidos.

Nesta dimensão sobressai também a atuação do Conselho do FUNDEB e do Conselho de Alimentação Escolar. A figura dos conselhos sagra-se como inovação da Constituição Federal de 1988, inaugurando maior participação e transparência na gestão pública. Estes preceitos colocam em relevo uma nova narrativa social e um laço entre Estado e Sociedade que necessitam da participação dos atores para sua viabilização.

A dimensão gestão de pessoas incorpora também as ações relativas a concursos públicos, capacitação de pessoal técnico administrativo, supervisão escolar, ajustes nos quadros funcionais, estágio probatório e sua publicização, o plano de carreira e o piso salarial. No tocante à dimensão conhecimentos e informações, prevê a informatização e qualificação da equipe da secretaria de educação para a consecução da avaliação do PAR.

Outra área do PAR relaciona-se à gestão de finanças, que espelha a transparência e o acompanhamento dos recursos públicos da educação. Envolve capacitação, orientação, encontros para assegurar a aplicação dos recursos vinculados à educação, a publicização e ampliação das redes de parceria. A democratização da gestão estatal é, segundo Abrucio (2010), um dos pilares da Constituição Federal de 1988, envolvendo deliberação e controle social.

$\mathrm{Na}$ dimensão que trata da Formação Inicial de Professores de Educação Básica, está previsto o acompanhamento e orientação. Dispõe sobre a necessidade de habilitar os docentes da educação infantil, consolidar um plano de formação, manter currículo atualizado, criar políticas de formação continuada para a Educação Infantil, Ensino Fundamental, Educação de Jovens e Adultos (EJA), Atendimento Educacional Especializado (AEE), e Educação Básica do Campo. Há que ponderar que nenhum sistema de ensino logrará avanços qualitativos sem investimentos massivos na formação docente e na sua valorização profissional.

O município também projeta a ampliação da educação integral nas escolas da Rede, conforme previsto no Plano Nacional de Educação (2014/2024).

O atendimento à demanda para a EJA mereceu destaque no Plano de Ações Articuladas, antevendo ações de planejamento, capacitação, acompanhamento e avaliação. Esta ação revela-se crucial, haja vista o fato de que o município possui 7\% de analfabetos, conforme BRASIL (2010).

A infraestrutura física e recursos pedagógicos foram pactuados pelo PAR no sentido de prover espaços condizentes com as ações educativas, bem como, a busca por outras fontes de recursos, como os do 
BNDES, antevendo a acessibilidade arquitetônica. Atualmente, para dar conta da demanda da Educação Infantil, o município utiliza espaços das escolas estaduais, o que fica dentro de ações de colaboração entre os governos.

Junto ao FNDE/MEC, o município propõe a aquisição de equipamentos materiais e recursos de áudio e vídeo para as escolas da rede, o que consta no Termo de Compromisso já assinado, mas sem liberação de recursos até o momento de finalização do estudo.

A descrição das metas no Plano de Ações Articuladas do município reflete a preocupação com recursos materiais e pedagógicas, bem como formação docente, de gestores e de técnico-administrativos. Entretanto, conforme apurado junto ao gestor da rede de ensino, os termos de compromisso assinados não garantiram a liberação de todos os recursos, especialmente recursos de informática e multimídia.

\section{Comentários finais}

A Constituição Federal de 1988, inaugura dispositivos que projetam, via pacto federativo, ações de assistência técnica e financeira da União aos entes federados. Neste estudo, focaram-se aquelas de assistência técnica voluntária, contidas no PAR, como possibilidade de maior equidade da educação.

Dois elementos são fundamentais na análise. O primeiro é a perspectiva da equidade, a qual é vista na ótica de Sen (2000, p.15): "[...] o que define uma sociedade justa é dispor de igualdade de oportunidades para todos, ou seja, dar a todos o mesmo ponto de partida". Tal enfoque remete à teoria da justiça, com potencial para minimizar as desigualdades, abrandando as injustiças.

Outro elemento sinalizador da complexidade da reflexão diz respeito às relações entre os entes federados na oferta educacional. Este estudo, ao refletir sobre a assistência voluntária de União, através do PAR, sinaliza para o rompimento com o modelo de corte clientelista e expõe nova pactuação e contratualização, via Termo de Compromisso assinado entre o FNDE e os entes subnacionais.

A análise do PAR de um município e o diálogo com o gestor municipal sublinha as ações mais prioritárias pactuadas pelo município, quais sejam, a educação infantil e o transporte escolar. Neste particular, é visível a influência da legislação que torna obrigatória a escolarização dos 4 aos 17 anos. Como o município tem a seu encargo a obrigatoriedade de atendimento das matrículas da faixa etária de 4 e 5 anos, percebe-se o esforço superlativo que a Prefeitura enfrenta em termos de cobertura, infraestrutura física, material e de corpo docente qualificado.

Após uma história de traços desiguais entre regiões, poderá o PAR, contribuir para maior equilíbrio entre os entes nacionais?

Adotar políticas educacionais de igualdade e equidade pode ser um percurso necessário para melhor qualidade de vida e para efetivar políticas igualitárias. Ainda que o Estado seja atingido pela globalização hegemônica, tem potencial e arranjos legais para atuar na redução das assimetrias sociais.

A descrição dos propósitos no Plano de Ações Articuladas do município reflete a preocupação com recursos materiais e pedagógicas, bem como a formação docente, de gestores e de técnico-administrativos. Entretanto, conforme apurado junto ao gestor da rede de ensino, Termos de Compromisso assinados não garantiram a liberação de recursos, especialmente recursos de informática e multimídia.

A assistência voluntária da União aos demais entes subnacionais, ao atender as demandas, tem potencial para minimizar os desequilíbrios intergovernamentais e regionais, contribuindo com a equidade da educação. 


\section{Referências}

ABRUCIO, F. L. A Dinâmica Federativa da Educação Brasileira, Diagnósticos e Propostas de Aperfeiçoamento. In: OLIVEIRA, R. P.; SANTANA, W. (Org.). Educação e Federalismo no Brasil: combater as desigualdades, garantir a diversidade. Brasília: Unesco, 2010. p. 39-70.

ARISTÓTELES. Ética a Nicômaco. São Paulo: Atlas Editora, 2009.

BRASIL. Censo Escolar, INEP, 2010.

Decreto n. 6.094, de 24 de abril de 2007. Dispõe sobre a implementação do Plano de Metas Compromisso Todos pela Educação, pela União Federal, em regime de colaboração com Municípios, Distrito Federal e Estados, e a participação das famílias e da comunidade, mediante programas e ações de assistência técnica e financeira, visando a mobilização social pela melhoria da qualidade da educação básica. Diário Oficial da República Federativa do Brasil, Brasília, 25 abr. 2007. P. 5.

. Lei n. 12.695, de 25 de julho de 2012. Dispõe sobre o apoio técnico ou financeiro da União no âmbito do Plano de Ações Articuladas [...] e dá outras providências. Diário Oficial da República Federativa do Brasil, Brasília, 26 jul. 2012. P. 1.

Lei n. 12.796, de 4 de abril de 2013. Altera a Lei no 9.394, de 20 de dezembro de 1996, que estabelece as diretrizes e bases da educação nacional, para dispor sobre a formação dos profissionais da educação e dar outras providências. Diário Oficial da República Federativa do Brasil, Brasília, 05 abr. 2013. P. 1.

CASSASUS, J. A escola e a desigualdade. Tradução de Lia Zatz. Brasília: Plano, 2002.

FARENZENA, N. Implementação de Planos de Ações Articuladas Municipais: marcos e trajetória de uma pesquisa de avaliação. In: FARENZENA, N. (Org.). Implementação de Plano de Ações Articuladas Municipais: uma avaliação em quatro estados brasileiros. Pelotas: Gráfica Universitária UFPEL, 2012b. p. 11-30.

FARENZENA, N. Relações Intergovernamentais nas Políticas de Educação Básica no Brasil: a assistência da união aos governos subnacionais em foco. Revista Uruguaya de Ciência Política, Montevideo, v. 21, n. 1, p. 183-212, 2012a.

FARENZENA, N.; MARCHAND, P. S. Relação Intergovenamentais na Educação à Luz do Conceito de Regulação. Cadernos de Pesquisa, São Paulo, v.43,n.150, p. 788-811, set./dez. 2013.

FERNANDES, R.; GREMAUD, A. P. Qualidade da educação: avaliação, indicadores e metas. In:VELOSO, F. et al. (Org.). Educação básica no Brasil: construindo o país do futuro. Rio de Janeiro: Elsevier, 2009.

MAFASSIOLI, A. S. Plano de Ações Articuladas. In: ANPED SUL - SEMINÁRIO DE PESQUISA EM EDUCAÇÃO DA REGIÃO SUL, 9, 2012, Caxias do sul. Anais... Caxias do Sul: Universidade de Caxias do Sul, 2012.

RAWLS, John. Justiça e Democracia. São Paulo: Martins Fontes, 2002.

RAWLS, John. Uma Teoria da Justiça. São Paulo: Martins Fontes, 2008.

SEN, Amartya. Desigualdade Reexaminada. Rio de Janeiro: Record, 2000.

Recebido em 30 de maio de 2016 | Aprovado em 27 de junho de 2016 